TITLE:

\title{
Epigenetic setting for long-term expression of estrogen receptor $a$ and androgen receptor in cells.
}

\author{
AUTHOR(S): \\ Imamura, Takuya
}

\section{CITATION:}

Imamura, Takuya. Epigenetic setting for long-term expression of estrogen receptor $a$ and androgen receptor in cells.. Hormones and behavior 2011,59(3): 345-352

ISSUE DATE:

2011-03

URL:

http://hdl.handle.net/2433/139527

\section{RIGHT:}

C 2010 Elsevier Inc.; この論文は出版社版でありません。引用の際には 出版社版をご確認ご利用ください。; This is not the published version. Please cite only the published version. 
2

3 Epigenetic setting for long-term expression of estrogen receptor $\alpha$ and androgen

4 receptor in cells

5

6

7 Takuya IMAMURA

8

9 Laboratory for Biodiversity, Global COE Program, Division of Biological Science,

10 Graduate School of Science, Kyoto University, Kitashirakawa-Oiwake, Sakyo-ku,

11 Kyoto 606-8502, Japan

12

13

14

15

16 Running Title: Epigenetics of estrogen receptor $\alpha$ in cells

17

18 Address correspondence to: Takuya Imamura, Laboratory for Biodiversity, Global COE

19 Program, Division of Biological Science, Graduate School of Science, Kyoto University,

20 Kitashirakawa-Oiwake, Sakyo-ku, Kyoto 606-8502, Japan. Phone: +81-75-753-4261;

21 FAX: +81-75-753-7667; e-mail: imamura@gcoe.biol.sci.kyoto-u.ac.jp 


\section{Abstract}

Epigenetic regulation of the nuclear estrogen and androgen receptors, ER and

3 AR, constitutes the molecular basis for the long-lasting effects of sex steroids on gene

4 expression in cells. The effects prevail at hundreds of gene loci in the proximity of

5 estrogen- and androgen-responsive elements and many more such loci through intra-

6 and even inter-chromosomal level regulation. Such a memory system should be active

7 in a flexible manner during the early development of vertebrates, and later replaced to

8 establish more stable marks on genomic DNA. In mammals, DNA methylation is

9 utilized as a very stable mark for silencing of the ER $\alpha$ and $\mathrm{AR}$ isoform expression

10 during cancer cell and normal brain development. The factors affecting the DNA

11 methylation of the ER $\alpha$ and AR genes in cells include estrogen and androgen. Since

12 testosterone induces brain masculinization through its aromatization to estradiol in a

13 narrow time window of the perinatal stage in rodents, the autoregulation of estrogen

14 receptors, especially the predominant form of ER $\alpha$, at the level of DNA methylation to

15 set up the "cell memory" affecting the sexually differentiated status of brain function

16 has been attracting increasing attention. The alternative usage of the androgen-AR

17 system for brain masculinization and estrogenic regulation of AR expression in some

18 species imply that the DNA methylation pattern of the AR gene can be established by

19 closely related but different systems for sex steroid-induced phenomena, including brain

20 masculinization.

21 Key words: estrogen receptor, androgen receptor, DNA methylation, brain 


\section{Introduction}

In mammals, sex-dependent compositions of the cells in the brains and the

3 nature of many patterns of behaviors cannot be attributed directly to genetic differences.

4 Rather, an important feature is that, in rodents for example, endocrine disturbance at the

5 fetal and/or postnatal stages irreversibly changes behaviors such as lordosis (in females)

6 and mounting (in males) that occur after the pubertal stage and are normally correlated

7 with the genetic sex. In some cases, lordosis can even be observed in males, and

8 mounting in females (Sodersten, 1978). In such phenomena, two classes of sex steroid

9 hormones produced largely in gonadal tissues, estrogen and androgen, play many

10 important physiological and pathological roles in a sex-dependent manner. In this

11 review, I summarize the present understanding of the cellular impacts of the "genomic"

12 effects of sex steroids, in particular the effect of estrogen through its interaction with its

13 predominant nuclear receptor, ER $\alpha$. Associated theoretical epigenetic pathways

14 triggered by estrogen and androgen and potentially leading to the differential expression

15 of mammalian behaviors will be featured.

17 Sex Steroid Hormones: Epigenetic Regulators of Brain Masculinization in

18 Rodents?

In general, estradiol (E2) and testosterone (T) circulate predominantly in adult

20 females and males of vertebrates, respectively. Therefore, one could readily assume that

21 these hormones set up the molecular basis to establish the endocrine circumstances and thereby influence the expression of sex-dependent behavior. For example, removal of 
1 the ovaries, the major source of E2, after the pubertal stage strongly deactivates the

2 hypothalamus-pituitary-gonadal (HPG) axis, thereby disturbing the pulsatile- and

3 surge-mode of luteinizing hormone secretion in rodents and many other mammals

4 including sheep, goat, cow and pig (Bronson, 1981; Goodman, 1978; Kraeling et al.,

5 1998; McCarthy and Swanson, 1976; Mori et al., 1987; Webb et al., 1981). In parallel,

6 the hypothalamus-pituitary-adrenal (HPA) axis is affected in ovariectomized animals

7 (Seale et al., 2004). Since these unregulated states are largely rescued by exogenous

8 treatment with E2 (Christian et al., 2005), estrogen has been focused on as an important

9 trigger for sexual reproduction and many sex-dependent behaviors. A similar situation is true for males, in that castration of the testes, the major source of $\mathrm{T}$, perturbs the HPG

11 and HPA axes, and T supplementation restores many sex-dependent behaviors (Putnam

12 et al., 2003). These losses and recoveries occur on a day- or week-scale (Lindzey et al.,

13 1998), and drastic changes of cell composition do not seem to be associated with these

14 experimental events. In contrast, cell composition is drastically affected during the

15 developmental stages. In fact, E2 triggers the cell fate specification at the perinatal stage

16 in rodent brains (Schwarz and McCarthy, 2008). For example, the medial preoptic area

17 (MPOA) and bed nucleus stria terminalis (BNST), which are famous sexually

18 dimorphic brain nuclei, show fewer apoptotic cells after estradiol benzoate (EB) or

19 testosterone propionate (TP) treatment at the perinatal stage in rodents (Chung et al.,

20 2000; Hsu et al., 2001). Cell proliferation and migration can also be associated with

21 estrogen signals (McCarthy, 2008). Paradoxically, cell death is increased in a subset of 
1 is the best example so far in which TUNEL-positive cells are increased after neonatal

2 treatment with EB or TP in male and female rats (Arai et al., 1994; Arai et al., 1996).

3 Changes of the survival and migration of the cells by the presence or absence of

4 estrogen could explain the phenomenon of "imprinting" of the brain at the critical

5 period, also known as brain masculinization (Cooke et al., 1998; McCarthy, 2008).

6 Since the nuclear estrogen receptor ER $\alpha$ can contribute to the molecular complex of

7 histone-interacting proteins and histone-modifying enzymes (Heinzel et al., 1997), the

8 highly ordered chromatin structure can be differentially established and somehow fixed

9 long-term in ER $\alpha$-positive cells. In this way, the estrogen-ER $\alpha$ complexes could change

10 particular cell characteristics rather than causing cells to die, proliferate, or migrate in

11 some cases. To decipher these complex ways of "imprinting" in specific brain regions, it

12 would be simplest to start by first dissecting the mechanisms involved at the cellular 13 level.

Until now, most studies on molecular mechanisms governing the epigenetic setting have focused on histone modifications and DNA methylation mainly occurring at the CG dinucleotide in animals. Histone modifications are commonly utilized in a

17 wide range of species, including single cell organisms (Jenuwein and Allis, 2001). On

18 the other hand, the overall DNA methylation level differs depending on the species. For 19 example, only trace amounts of methylcytosine can be found in Drosophila 20 melanogaster (Kunert et al., 2003; Lyko et al., 2000). In mammals, DNA methylation is

21 a fundamental mechanism that differentiates the gene expression pattern in the brain 22 (Imamura et al., 2001; Jones and Takai, 2001). Indeed, mutations in genes associated 
1 with DNA methylation have frequently been shown to lead to many defects in neural

2 systems. For example, mutations in MECP2, a methylcytosine interacting protein, is

3 known to cause Rett syndrome (Amir et al., 1999). Mutations in a de novo DNA

4 methyltransferase (DNMT), DNMT3B, lead to ICF syndrome (Hansen et al., 1999; Xu

5 et al., 1999). Both of these syndromes show some characteristics of neuronal disorders.

6 The DNA methylation system is also known to be critical for genomic imprinting

7 (Heard et al., 1999), transposon silencing (Bird and Wolffe, 1999; Walsh and Bestor,

8 1999), chromatin stability (Eden et al., 2003), and tissue-dependent gene expression

9 (Shiota et al., 2002). In mammals, DNA methylation imposes restraints on the

10 pluripotency because once the patterns are established during development they can be

11 maintained through cell division (Sharif et al., 2007). Conversely, some fishes, which

12 contain much lower DNA methylation activity (Cross et al., 1991), are found to easily

13 and reversibly change their sex status according to the environmental context (Grober

14 and Sunobe, 1996). These facts support the idea that sex-dependent patterns of

15 behaviors are established through epigenetic processes. The sex-dependent patterns of

16 mammalian behaviors could be acquired through highly irreversible processes during

17 development by exposure to sex steroid hormones. In particular, it could be

18 hypothesized that the long-term effects of the sex steroids at the developmental stage on

19 behaviors after puberty are somehow marked at the genome level.

21 Priming Effect of Sex Steroid Hormones on Gene Transcription in Cells

The biogenesis of E2 from $\mathrm{T}$ is accomplished by the catalytic action of 
1 aromatase $\mathrm{P} 450$. Although $\mathrm{ER} \alpha$ is the predominant nuclear receptor for estrogen, $\mathrm{ER} \beta$ is

2 known to be another nuclear receptor (Couse and Korach, 1999). So far, AR is the only

3 known receptor for androgen. In addition to these nuclear receptors, ER-X and two

4 G-protein-coupled receptors, GPR30 and Gq-mER, bind to estrogen to transduce the

5 estrogen signals rapidly to adjust the cellular status (Funakoshi et al., 2006; Qiu et al.,

6 2003; Qiu et al., 2006; Revankar et al., 2005; Toran-Allerand, 2005). The differential

7 presence of various forms of estrogen and androgen receptors in cells makes it difficult

8 to understand the whole picture of sex steroid signaling. Although membrane-bound

9 receptors might play some roles in gene regulation, it is simplest to first consider only the role of nuclear receptors in the epigenetic effects of estrogen and androgen.

Early work on the Xenopus vitellogenin gene identified a minimal estrogen

12 responsive element (ERE) core sequence composed of two 6-base asymmetrical 13 elements separated by three spacer nucleotides: 5'-GGTCAnnnTGACC-3'

14 (Klein-Hitpass et al., 1986). A similar but not identical structure has been found for the androgen responsive element (ARE). Most AREs conform to a consensus sequence composed of two 6-base asymmetrical elements separated by three spacer nucleotides:

18 Occupancy of ERE and ARE by the steroid-nuclear receptor complex can lead to the acute upregulation of the physically associated gene. There are many examples of acute upregulation by the estrogen-ER complex together with other nuclear transcription

21 factors (Gruber et al., 2004). Conversely, removal of steroid hormones also causes an acute decrease of gene transcription. However, there are examples in which 
1 supplementation of steroid hormones to ER $\alpha$-positive breast cells gradually upregulates

2 the cell cycle, followed by DNA methylation, histone modification, and microRNA

3 expression changes (Kovalchuk et al., 2007). These occurrences are associated with

4 transformation into hyperplastic states such as those in carcinomas and metastatic cells.

5 Another report showed that, on disruption of ER $\alpha$ signaling by small interfering RNA,

6 polycomb repressors and histone deacetylases (HDACs) are recruited to initiate stable

7 repression of the progesterone receptor (PR) gene, a known ER $\alpha$ target, in breast cancer

8 cells (Leu et al., 2004). In these cells, ER $\alpha$ repression is accompanied by PR mRNA

9 disappearance one day later. This event is also accompanied one week later by DNA

10 methylation of the PR promoter, leaving a stable mark that can be inherited by cancer

11 cell progeny. Reestablishing ER signaling alone is not sufficient to reactivate the PR

12 gene, rather, reactivation of the PR gene also requires DNA demethylation. The removal

13 of the nuclear estrogen signal induces progressive DNA methylation of multiple ER $\alpha$

14 targets in breast cancer genomes (Leu et al., 2004). Considering this kind of long-term

15 effect of sex steroid hormones on setting the target gene expression status, it would be

16 important to see the precise timeline of epigenetic alterations occurring in cells.

Since the identification of a canonical ERE, several computational

18 approaches have been undertaken to identify ER $\alpha$ target genes at the genome-wide level

19 (Bajic et al., 2003; Bourdeau et al., 2004). For example, in excess of 70,000 putative

20 EREs have been found in the human genome, over 17,000 of which are located within

$2115 \mathrm{~kb}$ of the transcription start sites of genes (Bourdeau et al., 2004). Six hundred sixty

22 of these are conserved between the mouse and human genomes, and a fraction of these 
1 have been confirmed experimentally to function as genuine ER $\alpha$-interacting sites. In

2 addition, imperfect EREs compared with the consensus sequence frequently show ER $\alpha$

3 binding activity (Gruber et al., 2004). Very recently, identifying long-distance chromatin

4 interactions with ER $\alpha$ has been attempted at the genome-wide level (Fullwood et al.,

5 2009). Using a combinatorial technique of chromatin immunoprecipitation and

6 ligation-mediated PCR, called ChIA-PET, DNA regions physically nearby the

$7 \quad$ ER $\alpha$-bound regions have been extensively sequenced. The results using E2-treated

8 MCF-7 cells showed 1451 intra-chromosomal and, surprisingly, 15 inter-chromosomal

9 overlapping clusters. Each of these more than one thousand clusters contains several

10 genes, many of which showed coordinated upregulation of their transcription by E2

11 treatment. The regions close to the ER $\alpha$-bound regions showed a tendency to rapidly

12 constitute active chromatin structures reminiscent of the active gene transcription in

13 response to E2. Even the genes in these clusters located relatively far from the

14 ER $\alpha$-bound region also seemed responsive to E2, resuming transcription two days later

15 on average. Such a tendency was not seen for the genes outside of the clusters.

16 Therefore, the time lag of transcription alteration between the immediate-early and

17 other genes raises the interesting possibility that genes in a cluster constitute an

18 intra-chromosomal loop structure for a commonly regulated epigenetic setting (Fig. 1).

19 In this model, a specific gene cluster could be organized to restrict the epigenetic effects

20 of the estrogen-ER $\alpha$ complex within a loop to strengthen the coordination of the

21 transcription, and this structure would isolate this effect to prevent leaky transcription of

22 the genes located outside of the loop. The differential ER $\alpha$-triggered epigenetic setting 
1 depending on cell type may account for the tissue- and sex-dependent differences of cell

2 fates resulting from various degrees of responsiveness to estrogen.

\section{Cell-Dependent Autoregulatory Loops of Sex-Steroid Receptor Genes}

Estrogen signaling frequently affects the ER $\alpha$ transcription in ER $\alpha$-positive

6 cells. That is, ER $\alpha$-positive cells can sensitize or desensitize their estrogen signaling

7 pathways in a cell-intrinsic manner. For example, a low dose of E2, given to

8 ovariectomized animals to mimic the preovulatory estrogen surges, acutely enhanced

9 ER $\alpha$ as well as PR gene expression in specific uterine cells (Ing and Tornesi, 1997).

10 These promoters were also modulated by E2 in estrogen-responsive breast cancer cell

11 lines (Donaghue et al., 1999; Saceda et al., 1988). In the case of T47D, ZR-75, and

12 EFM-19 breast cancer cells, E2 increased ER $\alpha$ expression. In contrast, the ER $\alpha$

13 promoter was downregulated by E2 in MCF-7 breast cancer cells, in which E2 reduced

14 the receptor expression. Therefore, ER $\alpha$ regulation by estrogen may strongly differ in

15 different cells. The kinetics of ER $\alpha$ mRNA and protein expression in MCF-7 cells were

16 investigated after acute treatment with E2 (Saceda et al., 1988). The data have

17 suggested that E2 downregulates ER $\alpha$ mRNA by inhibition of ER $\alpha$ gene transcription at

18 early times and by a posttranscriptional effect on receptor mRNA at later times. Actually,

19 three promoters have been identified for human ER $\alpha$. The use of the three promoters

20 was examined in ER-positive breast cancer cell lines, cell lines derived from other

21 malignancies, and some normal tissues (Donaghue et al., 1999). Many

22 estrogen-responsive breast cancer cells used all three promoters. Cell lines derived from 
1 other malignancies and other normal tissues that express lower levels of ER $\alpha$ showed

2 more selective promoter usage. This raised the possibility that the level of expression of

$3 \mathrm{ER} \alpha$ is determined by the number of promoters used, rather than the selective use of

4 specific promoters. However, the number of known alternative ER $\alpha$ promoters is still

5 growing in the human, mouse and rat (Kos et al., 2001; Wilson et al., 2008), and

6 therefore, the possibility that the selective usage of specific promoters accounts for the

$7 \quad$ tissue- or cell-specific ER $\alpha$ expression cannot be ruled out.

In rodents, ER $\alpha$ mRNA is expressed in several brain regions, including the

9 MPOA (Shughrue et al., 1992). In male mice, a high density of ER $\alpha$ was found in a small number of hypothalamic cells of the MPOA, arcuate, and ventromedial nuclei

11 (Agarwal et al., 2000). A low or medium density of ER $\alpha$ was observed in cells of the

12 lateral preoptic area, supraoptic nucleus, BNST, and in the central, medial and anterior

13 cortical amygdaloid nuclei. Estrogens are believed to downregulate their own receptors

14 in most rodent brain regions, because ovariectomy and subsequent EB supplementation very frequently increase and decrease the ER $\alpha$ mRNA level, respectively (Hamada et al., 2005; Lauber et al., 1991; Shughrue et al., 1992). This general tendency was also assessed with aromatase knockout (ArKO) mice in which conversion of $\mathrm{T}$ to $\mathrm{E} 2$ is

18 impaired (Agarwal et al., 2000). The number of cells containing ER $\alpha$ protein was 19 significantly increased in the MPOA of the ArKO male mice. Similarly, male rats 20 treated with an aromatase inhibitor escaped from the inhibitory effect of $\mathrm{T}$ on ER $\alpha$ 21 expression in many brain regions, suggesting that $\mathrm{T}$ functions through its aromatization 
1 estrogen can downregulate ER $\alpha$ in brain cells.

2

3

However, ER $\alpha$ regulation by estrogen seems to differ according to the brain region. For example, EB was shown to decrease immunostaining intensity for ER $\alpha$ in the ventrolateral hypothalamus and BNST, but not in the periventricular preoptic area or medial amygdala of female rats (DonCarlos et al., 1995; Lauber et al., 1991). Moreover, EB treatment fails to significantly downregulate ER $\alpha$ mRNA levels in male rats, in contrast to the downregulation in female rats (Lauber et al., 1991).

\section{DNA Methylation of the ERa Promoter}

To reconcile the mutually opposite effects of estrogen on ER $\alpha$ expression, namely, its upregulation and downregulation according to the cell type, it is necessary to think of the other factors that modulate the quantity of ER $\alpha$ mRNA. It should be noted that long-term deprivation of estrogen in the culture media of ER $\alpha$-positive breast cancer cells can generate ER $\alpha$-negative subclones that are completely insensitive to estrogen for their cell growth (Pink and Jordan, 1996). This phenomenon strongly suggests the involvement of an epigenetic mechanism to preset the local chromatin structure for the basal $\mathrm{ER} \alpha$ expression. In this context, formation of transcriptional repression complexes including DNMT, HDAC and/or methyl-CpG binding protein is emerging as an important mechanism in silencing a variety of methylated tissue-specific and imprinted genes (Imamura et al., 2001). In fact, methylation of the ER $\alpha \mathrm{CpG}$ island is associated with loss of ER $\alpha$ expression in human breast cancer cells (Ottaviano et al., 1994). Treatment of ER $\alpha$-negative human breast cancer cells with the DNMT1 inhibitor 
1 5-aza-2'-deoxycytidine (5-aza-dC) leads to ER $\alpha$ mRNA and protein re-expression

2 (Ferguson et al., 1995). Also, the HDAC inhibitor trichostatin A (TSA) could induce

3 ER $\alpha$ transcripts (Yang et al., 2000). In addition, the combination of 5-aza-dC and TSA

4 induced a synergistic increase in ER $\alpha$ transcripts, occurring concomitantly with

5 markedly reduced soluble DNMT1 expression and activity, partial demethylation of the

6 ER $\alpha \mathrm{CpG}$ island, and increased acetylation of histones $\mathrm{H} 3$ and $\mathrm{H} 4$. These data suggest

7 that the activities of both DNMT1 and HDAC are key regulators of

8 methylation-mediated ER $\alpha$ gene silencing.

9 It has been demonstrated that thousands of $\mathrm{CpG}$ islands show tissue- or 10 cell-dependent patterns of DNA methylation (Shiota et al., 2002). Therefore, distinct

11 DNA methylation patterns in the respective cells can establish or fix cellular phenotypes.

12 On the one hand, each differentiated cell maintains its DNA methylation pattern (Shiota 13 and Yanagimachi, 2002). On the other hand, dynamic DNA methylation changes occur

14 during development, and cell differentiation is always associated with DNA methylation

15 and demethylation, forming cell-specific patterns (Ohgane et al., 2002). DNA

16 demethylation occurs through either passive mechanisms by inhibiting the DNMT1 or

17 through active enzymatic reactions. Active demethylation has been observed in many

18 cells but the mechanisms involved are relatively unknown (Collas, 1998; Fremont et al.,

19 1997; Imamura et al., 2004; Jost et al., 1997; Jost and Jost, 1994; Jost et al., 1995; Jost

20 et al., 1999; Kim et al., 2009; Ma et al., 2009). Although long-term maintenance of

21 DNA methylation patterns is a prerequisite for an animal's life, the overall

22 methylcytosine content gradually decreases in parallel with aging processes. Since gene 
1 body regions account for only a small percentage of the genome, gain or loss of the

2 overall methylcytosine content might largely affect "bulk" sequences such as

3 transposable elements constituting heterochromatin structure to maintain chromosomal

4 stability. In line with this tendency, most cancer cells show a hypomethylated status at

5 the transposable elements (Baylin et al., 1998). Paradoxically, an overall decrease of

6 DNA methylation content is associated with local induction of the DNA methylation at

7 multiple gene loci (Baylin et al., 1998). Considering that the circulating and local

8 contents of sex steroid hormones dynamically change according to the developmental

9 and aging context, DNA methylation changes related to ER $\alpha$ expression could occur in various brain cells, including neurons, in a spatiotemporal manner.

11 In fact, recent studies have shown that the DNA methylation status of ER $\alpha$ in 12 physiologically normal cells differs during development depending on the cell type. In 13 the mouse cortex, ER $\alpha$ mRNA expression is high early in postnatal development but 14 declines starting at postnatal day (P) 10 and is virtually absent in the adult cortex. 15 Several regions of the ER $\alpha$ promoter displayed a significant increase in methylation at 16 P18 and P25 compared with P4 (Westberry et al., 2010). In the mouse cortex, DNMT3A 17 (the de novo DNMT) peaked at P10 and was decreased by P25. DNMT1 increased 18 across development and stayed high in the adult cortex. A chromatin 19 immunoprecipitation assay showed a correlation between association of MECP2 with 20 the ER $\alpha$ promoter and the increase in DNA methylation and decrease in ER $\alpha$ expression 21 after P10 (Westberry et al., 2010). 
1 pattern of the ER $\alpha$ promoter. Maternal care of rat pups can lead to long-term effects

2 affecting the life-long response to stress in the offspring (Liu et al., 1997). Mothers that

3 have high rates of licking and grooming behavior have offspring with a more modest

4 response to stress. Adult offspring of mothers that exhibit high licking and grooming

5 activity have increased expression of ER $\alpha$ mRNA in the MPOA, and this increased

6 expression is associated with less methylation at the ER $\alpha$ promoter, while the ER $\alpha$

7 promoter in offspring from low licking and grooming mothers is hypermethylated

8 (Francis et al., 1999). In addition, variations in the rates of licking and grooming are

9 inherited. Mothers with high rates of licking and grooming activity have pups that later exhibit similar behavior when they become mothers (Francis et al., 1999).

\section{A Model for the Estrogen Effect on ERa mRNA Expression}

With the analogy of brain learning, cells with the potential to transcribe ER $\alpha$ may memorize the surrounding estrogen availability for the expression of specialized cell function. In line with this idea, during $>8$ months of deprivation of E2 from the culture media, breast cancer cells with a low level of ER $\alpha$ protein gradually lose the ability of ER $\alpha$ transcription (Pink and Jordan, 1996). After 2-month resupplementation of E2 in the media, these cells occasionally recover ER $\alpha$ expression competence. Such cells show steady ER $\alpha$ upregulation by E2 treatment. On the other hand, different cells originating from the same organ but with relatively higher levels of ER $\alpha$ mRNA might

21 be affected by the possible destabilization activity of an E2-ER $\alpha$ complex that has been 
1 be possible if an excess amount of E2-ER $\alpha$ complex that could not enter into the

2 nucleus due to physical or biochemical blockage remained located in the cytoplasm.

3 Based on the several lines of information described above, a schematic representation of

4 possible ER $\alpha$-triggered alteration of the cell status is shown in Fig. 2.

Phases A and B: Starting from the low expression status of ER $\alpha$ at the early

6 stage, cells show the capacity to incorporate the extracellular estrogen signal and try to

7 amplify this signal by upregulation of ER $\alpha$. This phase could be in a learning state of

8 the cell in terms of establishing intra- and inter-chromosomal structures through the

9 interaction of increased E2-ER $\alpha$ complex with widespread ERE in the genome for the

10 large-scale epigenetic setting triggered by E2. After a considerable level of ER $\alpha$ is

11 reached, cells behave to maintain the estrogen signal to keep the equilibrium state,

12 which is reminiscent of the homeostatic state.

Phase C: During aging, overall DNA methylation and other chromatin

14 modification activities gradually decrease in cells, while gene loci including ER $\alpha$ are targeted by local DNA methylation activity. In parallel, circulating E2 also decreases.

16 This decrease within a certain time range is further memorized in cells to accelerate the

17 DNA methylation of the ER $\alpha$ promoter, which is also frequently seen in ER $\alpha$-negative 18 cancer cells.

Phase D: If cells do not have the capacity or chance to incorporate the

20 estrogen signals, a concomitant increase of general DNA methylation activity

21 specifically or non-specifically closes the chromatin structure at the ER $\alpha$ cis-regulatory regions by DNA methylation and/or histone modifications such as methylation at lysine 
19 of histone H3. Once cells learn the expression downregulation via DNA methylation

2 and other epigenetic modifications, such cells would rarely express ER $\alpha$, thereby

3 greatly reducing the possibility of its expression except after abnormal treatment such as

4 long-term exposure to estrogen.

The model shown here has been made based largely on cancer cell studies.

6 Since the estrogen regulation system varies widely, it would be valuable to test several

7 simple models of the phases described above. Of course, mechanisms mediating

8 epigenetic alterations may differ in postmitotic brain cells and cancer cells of different

9 origins. Nonetheless, it should be noted that acquiring the unmethylated status of the

10 ER $\alpha$ promoter by either passive mechanisms (lack of faithful replication of DNA

11 methylation patterns) or active epigenetic mechanisms (enzymatic mechanisms) is

12 prerequisite for sensing the estrogen signal in postmitotic cells as well as cancer cells.

13 Even in cells where estrogen can function to acutely downregulate the ER $\alpha$ transcription

14 as represented by phase $\mathrm{B}$, the $\mathrm{ER} \alpha$ promoter is expected to be in unmethylated status.

15 In other words, estrogen-sensing cells have learned to establish the unmethylated status

16 in the ER $\alpha$ promoter. On the other hand, once DNA methylation occurs at the ER $\alpha$

17 promoter during the course of development or aging as represented by phases $\mathrm{C}$ and $\mathrm{D}$,

18 it seems very hard to remove this methylation. Accordingly, defining the cells

19 represented by the phase A would greatly accelerate clarification of the mechanism of

20 brain masculinization. 
In many androgen target tissues, androgens promote downregulation of AR

2 mRNA levels (Hackenberg et al., 1992; Krongrad et al., 1991; Quarmby et al., 1990;

3 Shan et al., 1990; Wolf et al., 1993). The amount of AR mRNA has been shown to

4 increase with androgen withdrawal and to decrease below control levels after androgen

5 stimulation in rat ventral prostate, coagulating gland, epididymis, seminal vesicle,

6 kidney, and brain, and in several prostate cancer cell lines. In the case of the rat ventral

7 prostate, AR mRNA increased within $24 \mathrm{~h}$ after castration and remained elevated for 4

8 days (Quarmby et al., 1990). TP treatment beginning $24 \mathrm{~h}$ after this castration reduced

9 ventral prostate AR mRNA within $8 \mathrm{~h}$. In this case, E2 administration after castration

10 had no significant effect on prostatic AR mRNA. Although the general tendency is

11 androgen-mediated downregulation of AR, androgenic upregulation of AR mRNA has

12 also been observed in a few tissues (Antonio et al., 1999; Gonzalez-Cadavid et al.,

13 1993; Kerr et al., 1995; Khetawat et al., 2000; Nastiuk and Clayton, 1994; Wiren et al.,

14 1997), which is reminiscent of the diversified autoregulation of ER $\alpha$ by estrogen.

15 Administration of a non-aromatizable androgen, dihydrotestosterone (DHT), to

16 castrated male rats has been shown to upregulate AR levels in the bulbocavernosus and

17 levator ani muscles (Antonio et al., 1999). In humans, megakaryocyte and

18 erythroleukemia AR expression is upregulated dose-dependently by $\mathrm{T}$ (up to $10 \mathrm{nmol} / \mathrm{L}$ ),

19 but downregulated by a much higher level of $\mathrm{T}(100 \mathrm{nmo} / \mathrm{L})$ (Khetawat et al., 2000).

20 Treatment of osteoblastic cells with DHT increased AR mRNA steadily in a time- and

21 dose-dependent fashion (Wiren et al., 1997). Reporter assays with the proximal

225 '-flanking region of the human AR promoter reproduced this effect of DHT on RNA 
1 expression (Wiren et al., 1997).

In the brain, AR mRNA expression occurs predominantly in the hypothalamus.

3 The highest density of AR mRNA is localized in the central part of the MPOA and the

4 principal portion of the BNST (Handa et al., 1996). Castration of adult male rats causes

5 an increase in AR mRNA density in both brain areas. Therefore, the negative regulation

6 of the expression of AR by androgen seems to be largely restricted to the predominant

7 area of AR function. However, a situation similar to that of the differential

8 autoregulation of ER $\alpha$ together with estrogen could again be observed for AR. In fact,

9 comparable levels of AR mRNA can be found in specific cells of the hippocampus. CA1 pyramidal cells are AR-positive and form the major signal output of the hippocampal

11 trisynaptic circuit. A significant decrease occurs in the AR mRNA content of the

12 hippocampus in rats after castration or in intact male rats after daily injections of the AR

13 antagonist flutamide (Kerr et al., 1995).

It has been proposed that methylation of $\mathrm{CpG}$ sites in the $\mathrm{AR}$ promoter may influence the long-term but reversible inactivation of transcription of the AR gene in androgen-independent metastatic prostate cancers (Jarrard et al., 1998; Kinoshita et al.,

17 2000). Normal prostate epithelial cell strains showed no DNA methylation of the AR 18 gene. In contrast, increased methylation was seen in the AR expression-negative cell 19 lines Du145, DuPro, TSU-PR1, and PPC1, as well as in normal female breast and 20 ovarian tissues. Exposure of AR-negative prostate cancer cell lines to 5-aza-dC induced 21 the reexpression of AR mRNA in AR expression-negative cell lines (Jarrard et al., 1998). 
$2 \mathrm{CG}$ sites in the AR core promoter has been shown to be increased by TP, but decreased

3 by E2 (Kumar and Thakur, 2004a). These sex steroid hormones concomitantly affected

4 DNase I accessibility to the AR core promoter (Kumar and Thakur, 2004b), suggesting

5 that setting of the chromatin structure on the AR promoter occurs with ER $\alpha$ and AR. In

6 fact, in the adult male rat, androgen and estrogen act synergistically in the regulation of

7 male reproductive behaviors (Baum, 1979; Feder et al., 1974; Morali et al., 1977). In

8 the MPOA and BNST of the adult male rat, AR and ER $\alpha$ mRNAs have been found to be

9 distributed in unique but overlapping patterns (Handa et al., 1996). In this case, treatment of castrated adult males with DHT reversed the effects of castration on AR

11 mRNA in both the short- and long-term castrated animals, but had no effect on ER $\alpha$

12 mRNA in either of these brain nuclei, whereas EB treatment increased AR mRNA in the

13 long-term castrates only and decreased ER $\alpha$ mRNA in both long- and short-term

14 castrates. This suggests a complex regulation of AR in specific brain regions. So far,

15 little information is available about the DNA methylation pattern on the AR as well as

16 the ER $\alpha$ gene after the short- and long-term androgen exposure or removal. Nonetheless,

17 AR has been shown to regulate the masculinization of the mouse brain (Sato et al.,

18 2004). Furthermore, several lines of pharmacological evidence have suggested that AR

19 is the predominant target for androgen-triggered brain masculinization in some species.

20 In rhesus monkeys, prenatal administration of the nonaromatizable androgen DHT to

21 females caused coital masculinization as readily as $\mathrm{T}$ (Pomerantz et al., 1986). In a carnivore, the ferret, neonatal exposure to T, but not its metabolites E2 or DHT, caused 
1 coital masculinization (Baum, 1976; Baum et al., 1983; Baum et al., 1982). Therefore,

2 in addition to the setting of the chromatin modifications on ER $\alpha$, that on AR by

3 androgen and estrogen could cause comparable impacts on brain masculinization.

\section{$5 \quad$ Concluding Remarks}

6 Nuclear estrogen and androgen signaling pathways are very complex.

7 Diversified autoregulatory loops of ER $\alpha$ or AR caused by its direct interaction with 8 estrogen or androgen further make it difficult to understand the whole picture of sex

9 steroid signaling. Epigenetic modifications, especially DNA methylation of the ER $\alpha$ and AR gene regions, could partially explain the highly irreversible changes of cell

11 responsiveness to sex steroid hormones in mammals. Local epigenetic engineering of

$12 \mathrm{ER} \alpha$ and $\mathrm{AR}$, if it can be achieved, could be used to determine the exact degree of the 13 contribution of DNA methylation to cell fate specification during development and 14 aging in future studies (Imamura et al., 2004). This would be especially important for 15 making the next breakthrough in understanding the irreversibility of sex-dependent 16 behaviors.

\section{Acknowledgements}

I thank Elizabeth Nakajima for proofreading of this manuscript. Research in

20 the Imamura team is supported by the Global COE program A06 to Kyoto University

21 and Grant-in-Aids (Nos. 17052028, 19040029, and 18770008) from MEXT, Japan. 
1

2

4

5

6

\section{References}

Agarwal, V. R., Sinton, C. M., Liang, C., Fisher, C., German, D. C., Simpson, E. R., 2000. Upregulation of estrogen receptors in the forebrain of aromatase knockout (ArKO) mice. Mol Cell Endocrinol. 162, 9-16.

Amir, R. E., Van den Veyver, I. B., Wan, M., Tran, C. Q., Francke, U., Zoghbi, H. Y., 1999. Rett syndrome is caused by mutations in X-linked MECP2, encoding methyl-CpG-binding protein 2. Nat Genet. 23, 185-8.

Antonio, J., Wilson, J. D., George, F. W., 1999. Effects of castration and androgen treatment on androgen-receptor levels in rat skeletal muscles. J Appl Physiol. 87, 2016-9.

Arai, Y., Murakami, S., Nishizuka, M., 1994. Androgen enhances neuronal degeneration in the developing preoptic area: apoptosis in the anteroventral periventricular nucleus (AVPvN-POA). Horm Behav. 28, 313-9.

Arai, Y., Sekine, Y., Murakami, S., 1996. Estrogen and apoptosis in the developing sexually dimorphic preoptic area in female rats. Neurosci Res. 25, 403-7.

Bajic, V. B., Tan, S. L., Chong, A., Tang, S., Strom, A., Gustafsson, J. A., Lin, C. Y., Liu, E. T., 2003. Dragon ERE Finder version 2: A tool for accurate detection and analysis of estrogen response elements in vertebrate genomes. Nucleic Acids Res. 31, 3605-7.

Baum, M. J., 1976. Effects of testosterone propionate administered perinatally on sexual behavior of female ferrets. J Comp Physiol Psychol. 90, 399-410.

Baum, M. J., 1979. A comparison of the effects of methyltrienolone (R 1881) and 5 alpha-dihydrotestosterone on sexual behavior of castrated male rats. Horm Behav. 13, 165-74.

Baum, M. J., Canick, J. A., Erskine, M. S., Gallagher, C. A., Shim, J. H., 1983. Normal differentiation of masculine sexual behavior in male ferrets despite neonatal inhibition of brain aromatase or 5-alpha-reductase activity. Neuroendocrinology. $36,277-84$.

Baum, M. J., Gallagher, C. A., Martin, J. T., Damassa, D. A., 1982. Effects of testosterone, dihydrotestosterone, or estradiol administered neonatally on sexual behavior of female ferrets. Endocrinology. 111, 773-80.

Baylin, S. B., Herman, J. G., Graff, J. R., Vertino, P. M., Issa, J. P., 1998. Alterations in 
DNA methylation: a fundamental aspect of neoplasia. Adv Cancer Res. 72, 141-96.

Bird, A. P., Wolffe, A. P., 1999. Methylation-induced repression--belts, braces, and chromatin. Cell. 99, 451-4.

Bourdeau, V., Deschenes, J., Metivier, R., Nagai, Y., Nguyen, D., Bretschneider, N., Gannon, F., White, J. H., Mader, S., 2004. Genome-wide identification of high-affinity estrogen response elements in human and mouse. Mol Endocrinol. $18,1411-27$.

Bronson, F. H., 1981. The regulation of luteinizing hormone secretion by estrogen: relationships among negative feedback, surge potential, and male stimulation in juvenile, peripubertal, and adult female mice. Endocrinology. 108, 506-16.

Christian, C. A., Mobley, J. L., Moenter, S. M., 2005. Diurnal and estradiol-dependent changes in gonadotropin-releasing hormone neuron firing activity. Proc Natl Acad Sci U S A. 102, 15682-7.

Chung, W. C., Swaab, D. F., De Vries, G. J., 2000. Apoptosis during sexual differentiation of the bed nucleus of the stria terminalis in the rat brain. $\mathrm{J}$ Neurobiol. 43, 234-43.

Clancy, A. N., Michael, R. P., 1994. Effects of testosterone and aromatase inhibition on estrogen receptor-like immunoreactivity in male rat brain. Neuroendocrinology. $59,552-60$.

Collas, P., 1998. Modulation of plasmid DNA methylation and expression in zebrafish embryos. Nucleic Acids Res. 26, 4454-61.

Cooke, B., Hegstrom, C. D., Villeneuve, L. S., Breedlove, S. M., 1998. Sexual differentiation of the vertebrate brain: principles and mechanisms. Front Neuroendocrinol. 19, 323-62.

Couse, J. F., Korach, K. S., 1999. Estrogen receptor null mice: what have we learned and where will they lead us? Endocr Rev. 20, 358-417.

Cross, S., Kovarik, P., Schmidtke, J., Bird, A., 1991. Non-methylated islands in fish genomes are GC-poor. Nucleic Acids Res. 19, 1469-74.

Donaghue, C., Westley, B. R., May, F. E., 1999. Selective promoter usage of the human estrogen receptor-alpha gene and its regulation by estrogen. Mol Endocrinol. 13, 1934-50.

DonCarlos, L. L., Malik, K., Morrell, J. I., 1995. Region-specific effects of ovarian 
hormones on estrogen receptor immunoreactivity. Neuroreport. 6, 2054-8.

Eden, A., Gaudet, F., Waghmare, A., Jaenisch, R., 2003. Chromosomal instability and tumors promoted by DNA hypomethylation. Science. 300, 455.

Feder, H. H., Naftolin, F., Ryan, K. J., 1974. Male and female sexual responses in male rats given estradiol benzoate and 5 alpha-androstan-17 beta-ol-3-one propionate. Endocrinology. 94, 136-41.

Ferguson, A. T., Lapidus, R. G., Baylin, S. B., Davidson, N. E., 1995. Demethylation of the estrogen receptor gene in estrogen receptor-negative breast cancer cells can reactivate estrogen receptor gene expression. Cancer Res. 55, 2279-83.

Francis, D., Diorio, J., Liu, D., Meaney, M. J., 1999. Nongenomic transmission across generations of maternal behavior and stress responses in the rat. Science. 286, 1155-8.

Fremont, M., Siegmann, M., Gaulis, S., Matthies, R., Hess, D., Jost, J. P., 1997. Demethylation of DNA by purified chick embryo 5-methylcytosine-DNA glycosylase requires both protein and RNA. Nucleic Acids Res. 25, 2375-80.

Fullwood, M. J., Liu, M. H., Pan, Y. F., Liu, J., Xu, H., Mohamed, Y. B., Orlov, Y. L., Velkov, S., Ho, A., Mei, P. H., Chew, E. G., Huang, P. Y., Welboren, W. J., Han, Y., Ooi, H. S., Ariyaratne, P. N., Vega, V. B., Luo, Y., Tan, P. Y., Choy, P. Y., Wansa, K. D., Zhao, B., Lim, K. S., Leow, S. C., Yow, J. S., Joseph, R., Li, H., Desai, K. V., Thomsen, J. S., Lee, Y. K., Karuturi, R. K., Herve, T., Bourque, G., Stunnenberg, H. G., Ruan, X., Cacheux-Rataboul, V., Sung, W. K., Liu, E. T., Wei, C. L., Cheung, E., Ruan, Y., 2009. An oestrogen-receptor-alpha-bound human chromatin interactome. Nature. 462, 58-64.

Funakoshi, T., Yanai, A., Shinoda, K., Kawano, M. M., Mizukami, Y., 2006. G protein-coupled receptor 30 is an estrogen receptor in the plasma membrane. Biochem Biophys Res Commun. 346, 904-10.

Gonzalez-Cadavid, N., Vernet, D., Fuentes Navarro, A., Rodriguez, J. A., Swerdloff, R. S., Rajfer, J., 1993. Up-regulation of the levels of androgen receptor and its mRNA by androgens in smooth-muscle cells from rat penis. Mol Cell Endocrinol. 90, 219-29.

Goodman, R. L., 1978. A quantitative analysis of the physiological role of estradiol and progesterone in the control of tonic and surge secretion of luteinizing hormone in the rat. Endocrinology. 102, 142-50. 
1 Grober, M. S., Sunobe, T., 1996. Serial adult sex change involves rapid and reversible changes in forebrain neurochemistry. Neuroreport. 7, 2945-9.

Gruber, C. J., Gruber, D. M., Gruber, I. M., Wieser, F., Huber, J. C., 2004. Anatomy of the estrogen response element. Trends Endocrinol Metab. 15, 73-8.

Hackenberg, R., Hawighorst, T., Filmer, A., Slater, E. P., Bock, K., Beato, M., Schulz, K. D., 1992. Regulation of androgen receptor mRNA and protein level by steroid hormones in human mammary cancer cells. J Steroid Biochem Mol Biol. 43, 599-607.

Hamada, T., Wada-Kiyama, Y., Sakuma, Y., 2005. Visualizing forebrain-specific usage of an estrogen receptor alpha promoter for receptor downregulation in the rat. Brain Res Mol Brain Res. 139, 42-51.

Handa, R. J., Kerr, J. E., DonCarlos, L. L., McGivern, R. F., Hejna, G., 1996. Hormonal regulation of androgen receptor messenger RNA in the medial preoptic area of the male rat. Brain Res Mol Brain Res. 39, 57-67.

Hansen, R. S., Wijmenga, C., Luo, P., Stanek, A. M., Canfield, T. K., Weemaes, C. M., Gartler, S. M., 1999. The DNMT3B DNA methyltransferase gene is mutated in the ICF immunodeficiency syndrome. Proc Natl Acad Sci U S A. 96, 14412-7.

Heard, E., Mongelard, F., Arnaud, D., Avner, P., 1999. Xist yeast artificial chromosome transgenes function as $\mathrm{X}$-inactivation centers only in multicopy arrays and not as single copies. Mol Cell Biol. 19, 3156-66.

Heinzel, T., Lavinsky, R. M., Mullen, T. M., Soderstrom, M., Laherty, C. D., Torchia, J., Yang, W. M., Brard, G., Ngo, S. D., Davie, J. R., Seto, E., Eisenman, R. N., Rose, D. W., Glass, C. K., Rosenfeld, M. G., 1997. A complex containing N-CoR, $\mathrm{mSin} 3$ and histone deacetylase mediates transcriptional repression. Nature. 387, 43-8.

Hsu, H. K., Yang, R. C., Shih, H. C., Hsieh, Y. L., Chen, U. Y., Hsu, C., 2001. Prenatal exposure of testosterone prevents SDN-POA neurons of postnatal male rats from apoptosis through NMDA receptor. J Neurophysiol. 86, 2374-80.

Imamura, T., Ohgane, J., Ito, S., Ogawa, T., Hattori, N., Tanaka, S., Shiota, K., 2001. $\mathrm{CpG}$ island of rat sphingosine kinase-1 gene: tissue-dependent DNA methylation status and multiple alternative first exons. Genomics. 76, 117-25.

Imamura, T., Yamamoto, S., Ohgane, J., Hattori, N., Tanaka, S., Shiota, K., 2004. Non-coding RNA directed DNA demethylation of Sphk1 CpG island. Biochem 
Biophys Res Commun. 322, 593-600.

Ing, N. H., Tornesi, M. B., 1997. Estradiol up-regulates estrogen receptor and progesterone receptor gene expression in specific ovine uterine cells. Biol Reprod. 56, 1205-15.

Jarrard, D. F., Kinoshita, H., Shi, Y., Sandefur, C., Hoff, D., Meisner, L. F., Chang, C., Herman, J. G., Isaacs, W. B., Nassif, N., 1998. Methylation of the androgen receptor promoter $\mathrm{CpG}$ island is associated with loss of androgen receptor expression in prostate cancer cells. Cancer Res. 58, 5310-4.

Jenuwein, T., Allis, C. D., 2001. Translating the histone code. Science. 293, 1074-80.

Jones, P. A., Takai, D., 2001. The role of DNA methylation in mammalian epigenetics. Science. 293, 1068-70.

Jost, J. P., Fremont, M., Siegmann, M., Hofsteenge, J., 1997. The RNA moiety of chick embryo 5-methylcytosine- DNA glycosylase targets DNA demethylation. Nucleic Acids Res. 25, 4545-50.

Jost, J. P., Jost, Y. C., 1994. Transient DNA demethylation in differentiating mouse myoblasts correlates with higher activity of 5-methyldeoxycytidine excision repair. J Biol Chem. 269, 10040-3.

Jost, J. P., Siegmann, M., Sun, L., Leung, R., 1995. Mechanisms of DNA demethylation in chicken embryos. Purification and properties of a 5-methylcytosine-DNA glycosylase. J Biol Chem. 270, 9734-9.

Jost, J. P., Siegmann, M., Thiry, S., Jost, Y. C., Benjamin, D., Schwarz, S., 1999. A re-investigation of the ribonuclease sensitivity of a DNA demethylation reaction in chicken embryo and G8 mouse myoblasts. FEBS Lett. 449, 251-4.

Kaneko, K. J., Furlow, J. D., Gorski, J., 1993. Involvement of the coding sequence for the estrogen receptor gene in autologous ligand-dependent down-regulation. Mol Endocrinol. 7, 879-88.

Kerr, J. E., Allore, R. J., Beck, S. G., Handa, R. J., 1995. Distribution and hormonal regulation of androgen receptor (AR) and $A R$ messenger ribonucleic acid in the rat hippocampus. Endocrinology. 136, 3213-21.

Khetawat, G., Faraday, N., Nealen, M. L., Vijayan, K. V., Bolton, E., Noga, S. J., Bray, P. F., 2000. Human megakaryocytes and platelets contain the estrogen receptor beta and androgen receptor (AR): testosterone regulates AR expression. Blood. 95, 2289-96. 
1 Kim, M. S., Kondo, T., Takada, I., Youn, M. Y., Yamamoto, Y., Takahashi, S., Matsumoto, T., Fujiyama, S., Shirode, Y., Yamaoka, I., Kitagawa, H., Takeyama, K., Shibuya, H., Ohtake, F., Kato, S., 2009. DNA demethylation in hormone-induced transcriptional derepression. Nature. 461, 1007-12.

Kinoshita, H., Shi, Y., Sandefur, C., Meisner, L. F., Chang, C., Choon, A., Reznikoff, C. R., Bova, G. S., Friedl, A., Jarrard, D. F., 2000. Methylation of the androgen receptor minimal promoter silences transcription in human prostate cancer. Cancer Res. 60, 3623-30.

Klein-Hitpass, L., Schorpp, M., Wagner, U., Ryffel, G. U., 1986. An estrogen-responsive element derived from the 5' flanking region of the Xenopus vitellogenin A2 gene functions in transfected human cells. Cell. 46, 1053-61.

Kos, M., Reid, G., Denger, S., Gannon, F., 2001. Minireview: genomic organization of the human ERalpha gene promoter region. Mol Endocrinol. 15, 2057-63.

Kovalchuk, O., Tryndyak, V. P., Montgomery, B., Boyko, A., Kutanzi, K., Zemp, F., Warbritton, A. R., Latendresse, J. R., Kovalchuk, I., Beland, F. A., Pogribny, I. P., 2007. Estrogen-induced rat breast carcinogenesis is characterized by alterations in DNA methylation, histone modifications and aberrant microRNA expression. Cell Cycle. 6, 2010-8.

Kraeling, R. R., Johnson, B., Barb, C. R., Rampacek, G. B., 1998. Evidence for a luteinizing hormone surge center in the hypothalamus of the pig. Biol Reprod. 58, 1199-205.

Krongrad, A., Wilson, C. M., Wilson, J. D., Allman, D. R., McPhaul, M. J., 1991. Androgen increases androgen receptor protein while decreasing receptor mRNA in LNCaP cells. Mol Cell Endocrinol. 76, 79-88.

Kumar, R. C., Thakur, M. K., 2004a. Androgen receptor mRNA is inversely regulated by testosterone and estradiol in adult mouse brain. Neurobiol Aging. 25, 925-33.

Kumar, R. C., Thakur, M. K., 2004b. Sex steroids reduce DNaseI accessibility of androgen receptor promoter in adult male mice brain. Brain Res Mol Brain Res. $131,1-7$.

Kunert, N., Marhold, J., Stanke, J., Stach, D., Lyko, F., 2003. A Dnmt2-like protein mediates DNA methylation in Drosophila. Development. 130, 5083-90.

Lauber, A. H., Mobbs, C. V., Muramatsu, M., Pfaff, D. W., 1991. Estrogen receptor messenger RNA expression in rat hypothalamus as a function of genetic sex and 
estrogen dose. Endocrinology. 129, 3180-6.

Leu, Y. W., Yan, P. S., Fan, M., Jin, V. X., Liu, J. C., Curran, E. M., Welshons, W. V., Wei, S. H., Davuluri, R. V., Plass, C., Nephew, K. P., Huang, T. H., 2004. Loss of estrogen receptor signaling triggers epigenetic silencing of downstream targets in breast cancer. Cancer Res. 64, 8184-92.

Lindzey, J., Wetsel, W. C., Couse, J. F., Stoker, T., Cooper, R., Korach, K. S., 1998. Effects of castration and chronic steroid treatments on hypothalamic gonadotropin-releasing hormone content and pituitary gonadotropins in male wild-type and estrogen receptor-alpha knockout mice. Endocrinology. 139, 4092-101.

Liu, D., Diorio, J., Tannenbaum, B., Caldji, C., Francis, D., Freedman, A., Sharma, S., Pearson, D., Plotsky, P. M., Meaney, M. J., 1997. Maternal care, hippocampal glucocorticoid receptors, and hypothalamic-pituitary-adrenal responses to stress. Science. 277, 1659-62.

Lyko, F., Ramsahoye, B. H., Jaenisch, R., 2000. DNA methylation in Drosophila melanogaster. Nature. 408, 538-40.

Ma, D. K., Jang, M. H., Guo, J. U., Kitabatake, Y., Chang, M. L., Pow-Anpongkul, N., Flavell, R. A., Lu, B., Ming, G. L., Song, H., 2009. Neuronal activity-induced Gadd45b promotes epigenetic DNA demethylation and adult neurogenesis. Science. 323, 1074-7.

McCarthy, M. M., 2008. Estradiol and the developing brain. Physiol Rev. 88, 91-124.

McCarthy, M. S., Swanson, L. V., 1976. Serum LH concentration following castration, steroid hormone and gonadotropin releasing hormone treatment in the male bovine. J Anim Sci. 43, 151-8.

Morali, G., Larsson, K., Beyer, C., 1977. Inhibition of testosterone-induced sexual behavior in the castrated male rat by aromatase blockers. Horm Behav. 9, 203-13.

Mori, Y., Tanaka, M., Maeda, K., Hoshino, K., Kano, Y., 1987. Photoperiodic modification of negative and positive feedback effects of oestradiol on LH secretion in ovariectomized goats. J Reprod Fertil. 80, 523-9.

Nastiuk, K. L., Clayton, D. F., 1994. Seasonal and tissue-specific regulation of canary androgen receptor messenger ribonucleic acid. Endocrinology. 134, 640-9.

Ohgane, J., Hattori, N., Oda, M., Tanaka, S., Shiota, K., 2002. Differentiation of 
trophoblast lineage is associated with DNA methylation and demethylation. Biochem Biophys Res Commun. 290, 701-6.

Ottaviano, Y. L., Issa, J. P., Parl, F. F., Smith, H. S., Baylin, S. B., Davidson, N. E., 1994. Methylation of the estrogen receptor gene $\mathrm{CpG}$ island marks loss of estrogen receptor expression in human breast cancer cells. Cancer Res. 54, 2552-5.

Pink, J. J., Jordan, V. C., 1996. Models of estrogen receptor regulation by estrogens and antiestrogens in breast cancer cell lines. Cancer Res. 56, 2321-30.

Pomerantz, S. M., Goy, R. W., Roy, M. M., 1986. Expression of male-typical behavior in adult female pseudohermaphroditic rhesus: comparisons with normal males and neonatally gonadectomized males and females. Horm Behav. 20, 483-500.

Putnam, S. K., Sato, S., Hull, E. M., 2003. Effects of testosterone metabolites on copulation and medial preoptic dopamine release in castrated male rats. Horm Behav. 44, 419-26.

Qiu, J., Bosch, M. A., Tobias, S. C., Grandy, D. K., Scanlan, T. S., Ronnekleiv, O. K., Kelly, M. J., 2003. Rapid signaling of estrogen in hypothalamic neurons involves a novel G-protein-coupled estrogen receptor that activates protein kinase C. J Neurosci. 23, 9529-40.

Qiu, J., Bosch, M. A., Tobias, S. C., Krust, A., Graham, S. M., Murphy, S. J., Korach, K. S., Chambon, P., Scanlan, T. S., Ronnekleiv, O. K., Kelly, M. J., 2006. A G-protein-coupled estrogen receptor is involved in hypothalamic control of energy homeostasis. J Neurosci. 26, 5649-55.

Quarmby, V. E., Yarbrough, W. G., Lubahn, D. B., French, F. S., Wilson, E. M., 1990. Autologous down-regulation of androgen receptor messenger ribonucleic acid. Mol Endocrinol. 4, 22-8.

Revankar, C. M., Cimino, D. F., Sklar, L. A., Arterburn, J. B., Prossnitz, E. R., 2005. A transmembrane intracellular estrogen receptor mediates rapid cell signaling. Science. 307, 1625-30.

Saceda, M., Lippman, M. E., Chambon, P., Lindsey, R. L., Ponglikitmongkol, M., Puente, M., Martin, M. B., 1988. Regulation of the estrogen receptor in MCF-7 cells by estradiol. Mol Endocrinol. 2, 1157-62.

Sato, T., Matsumoto, T., Kawano, H., Watanabe, T., Uematsu, Y., Sekine, K., Fukuda, T., Aihara, K., Krust, A., Yamada, T., Nakamichi, Y., Yamamoto, Y., Nakamura, T., Yoshimura, K., Yoshizawa, T., Metzger, D., Chambon, P., Kato, S., 2004. Brain 
masculinization requires androgen receptor function. Proc Natl Acad Sci U S A. 101, 1673-8.

Schwarz, J. M., McCarthy, M. M., 2008. Cellular mechanisms of estradiol-mediated masculinization of the brain. J Steroid Biochem Mol Biol. 109, 300-6.

Seale, J. V., Wood, S. A., Atkinson, H. C., Harbuz, M. S., Lightman, S. L., 2004. Gonadal steroid replacement reverses gonadectomy-induced changes in the corticosterone pulse profile and stress-induced hypothalamic-pituitary-adrenal axis activity of male and female rats. J Neuroendocrinol. 16, 989-98.

Shan, L. X., Rodriguez, M. C., Janne, O. A., 1990. Regulation of androgen receptor protein and mRNA concentrations by androgens in rat ventral prostate and seminal vesicles and in human hepatoma cells. Mol Endocrinol. 4, 1636-46.

Sharif, J., Muto, M., Takebayashi, S., Suetake, I., Iwamatsu, A., Endo, T. A., Shinga, J., Mizutani-Koseki, Y., Toyoda, T., Okamura, K., Tajima, S., Mitsuya, K., Okano, M., Koseki, H., 2007. The SRA protein Np95 mediates epigenetic inheritance by recruiting Dnmt1 to methylated DNA. Nature. 450, 908-12.

Shiota, K., Kogo, Y., Ohgane, J., Imamura, T., Urano, A., Nishino, K., Tanaka, S., Hattori, N., 2002. Epigenetic marks by DNA methylation specific to stem, germ and somatic cells in mice. Genes Cells. 7, 961-9.

Shiota, K., Yanagimachi, R., 2002. Epigenetics by DNA methylation for development of normal and cloned animals. Differentiation. 69, 162-6.

Shughrue, P. J., Bushnell, C. D., Dorsa, D. M., 1992. Estrogen receptor messenger ribonucleic acid in female rat brain during the estrous cycle: a comparison with ovariectomized females and intact males. Endocrinology. 131, 381-8.

Sodersten, P., 1978. Effects of anti-oestrogen treatment of neonatal male rats on lordosis behaviour and mounting behaviour in the adult. J Endocrinol. 76, 241-9.

Toran-Allerand, C. D., 2005. Estrogen and the brain: beyond ER-alpha, ER-beta, and 17beta-estradiol. Ann N Y Acad Sci. 1052, 136-44.

Walsh, C. P., Bestor, T. H., 1999. Cytosine methylation and mammalian development. Genes Dev. 13, 26-34.

Webb, R., England, B. G., Fitzpatrick, K. E., 1981. Control of the preovulatory gonadotropin surge in the ewe. Endocrinology. 108, 1178-85.

Westberry, J. M., Trout, A. L., Wilson, M. E., 2010. Epigenetic regulation of estrogen receptor alpha gene expression in the mouse cortex during early postnatal 
development. Endocrinology. 151, 731-40.

Wilson, M. E., Westberry, J. M., Prewitt, A. K., 2008. Dynamic regulation of estrogen receptor-alpha gene expression in the brain: a role for promoter methylation? Front Neuroendocrinol. 29, 375-85.

Wiren, K. M., Zhang, X., Chang, C., Keenan, E., Orwoll, E. S., 1997. Transcriptional up-regulation of the human androgen receptor by androgen in bone cells. Endocrinology. 138, 2291-300.

D. A., Herzinger, T., Hermeking, H., Blaschke, D., Horz, W., 1993. Transcriptional and posttranscriptional regulation of human androgen receptor expression by androgen. Mol Endocrinol. 7, 924-36.

Xu, G. L., Bestor, T. H., Bourc'his, D., Hsieh, C. L., Tommerup, N., Bugge, M., Hulten, M., Qu, X., Russo, J. J., Viegas-Pequignot, E., 1999. Chromosome instability and immunodeficiency syndrome caused by mutations in a DNA methyltransferase gene. Nature. 402, 187-91.

Yang, X., Ferguson, A. T., Nass, S. J., Phillips, D. L., Butash, K. A., Wang, S. M., Herman, J. G., Davidson, N. E., 2000. Transcriptional activation of estrogen receptor alpha in human breast cancer cells by histone deacetylase inhibition. Cancer Res. 60, 6890-4. 


\section{$1 \quad$ Figure Legends}

2

3 Figure 1. ER $\alpha$ target gene regulation by chromatin setting through ERE-ER $\alpha$

4 interactions.

5 In this model, E2 alters the chromatin structure by E2-ER $\alpha$ association with the estrogen

6 responsive element (ERE). On the ERE-ER $\alpha$ complex, several cofactors are recruited to

7 concordantly establish the highly ordered chromatin structure. The E2 effect is exerted

8 on many genes within an ERE-containing cluster. Genes proximal to the ERE tend to

9 show rapid upregulation whereas expression of distal genes occurs later on. The ERE

10 effect could be restricted by insulators to prevent changes of the expression of genes

11 located outside of the cluster.

13 Figure 2. Cells with differential ER $\alpha$ expression setting by estrogen and DNA

14 methylation during development and senescence.

15 Panel A indicates a cell in which E2 starts being incorporated at early developmental

16 stages, such as the perinatal stage of mice corresponding to the critical period of brain

17 masculinization. ER $\alpha$ could enter into the nucleus to upregulate the $\mathrm{ER} \alpha$ mRNA

18 expression. After a number of cycles of synergistic increase of ER $\alpha$ by an increase of

19 circulating E2, E2-ER $\alpha$ association with ER $\alpha$ mRNA occurs in the cytoplasm. This kind

20 of blockage and other biochemical signals could prevent the entry of E2-ER $\alpha$ into the

21 nucleus, as shown in panel B. These negative regulations of ER $\alpha$ mRNA expression

22 allow the stable existence of ER $\alpha$ in a cell. Panel $\mathrm{C}$ represents an aged cell in which 
1 overall DNA methylation activities, represented by hexagons, are diminishing. Decrease

2 of the circulating E2 is accompanied by senescence. Long-term decrease of E2 and the

3 resultant reduced content of ER $\alpha$ could be sensed by the cell, which would as a result

4 change the DNA methylation status of the ER $\alpha$ promoter from hypomethylated (open

5 lollipops) to hypermethylated (filled lollipops) according to the lack of need for ER $\alpha$

6 even if the overall DNA methylation level were lowered. In contrast to the senescence

7 stage, developmental stage cells contain much higher DNA methylation activities which

8 react with genes as well as heterochromatin regions. If a cell is not exposed to E2, there

9 is no chance of ER $\alpha$ expression, leading to long-term repression by DNA methylation

10 and other modifications reminiscent of the closed chromatin structure, as shown in 11 panel D. 
55-京就大学

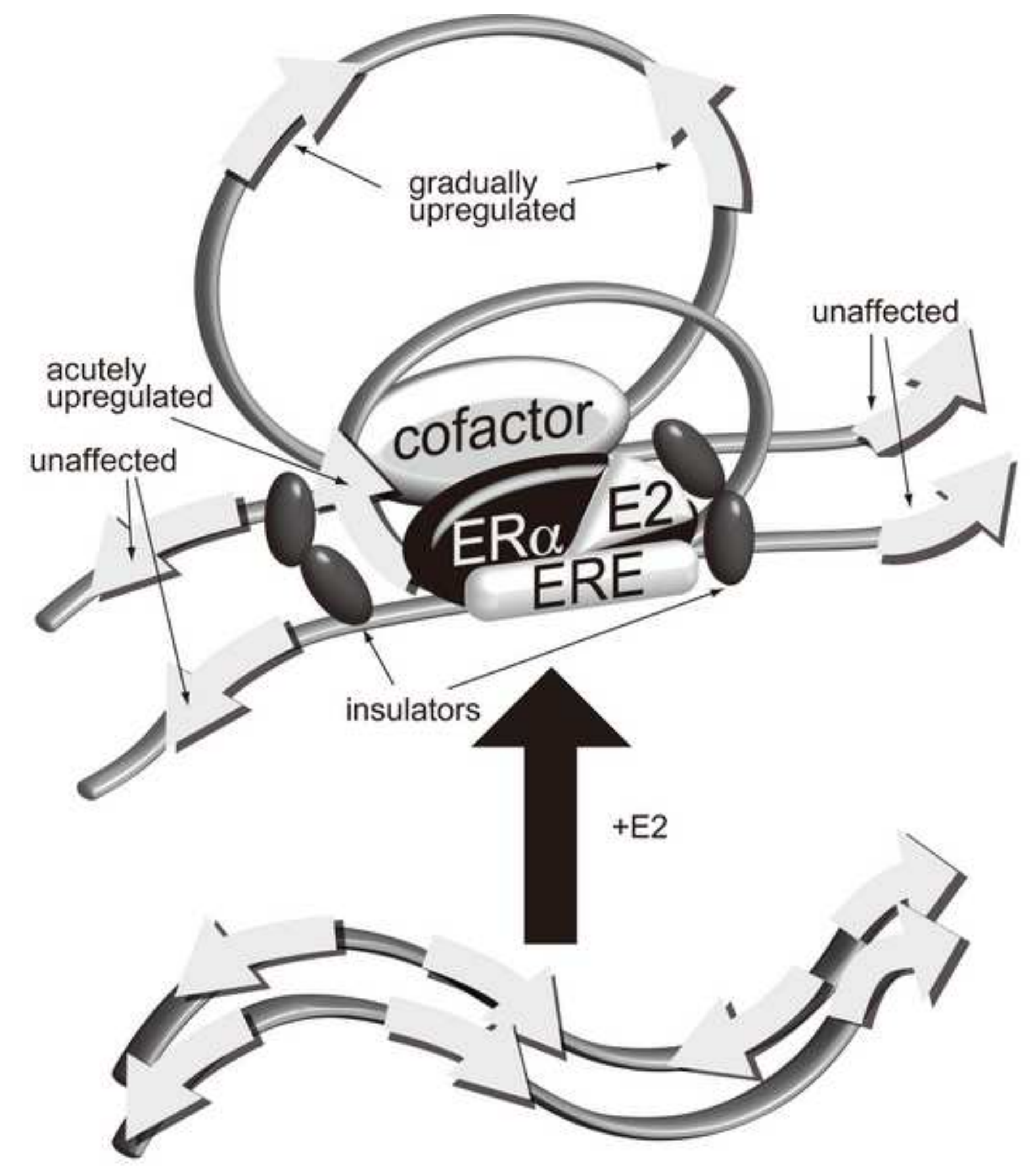

Figure 1 

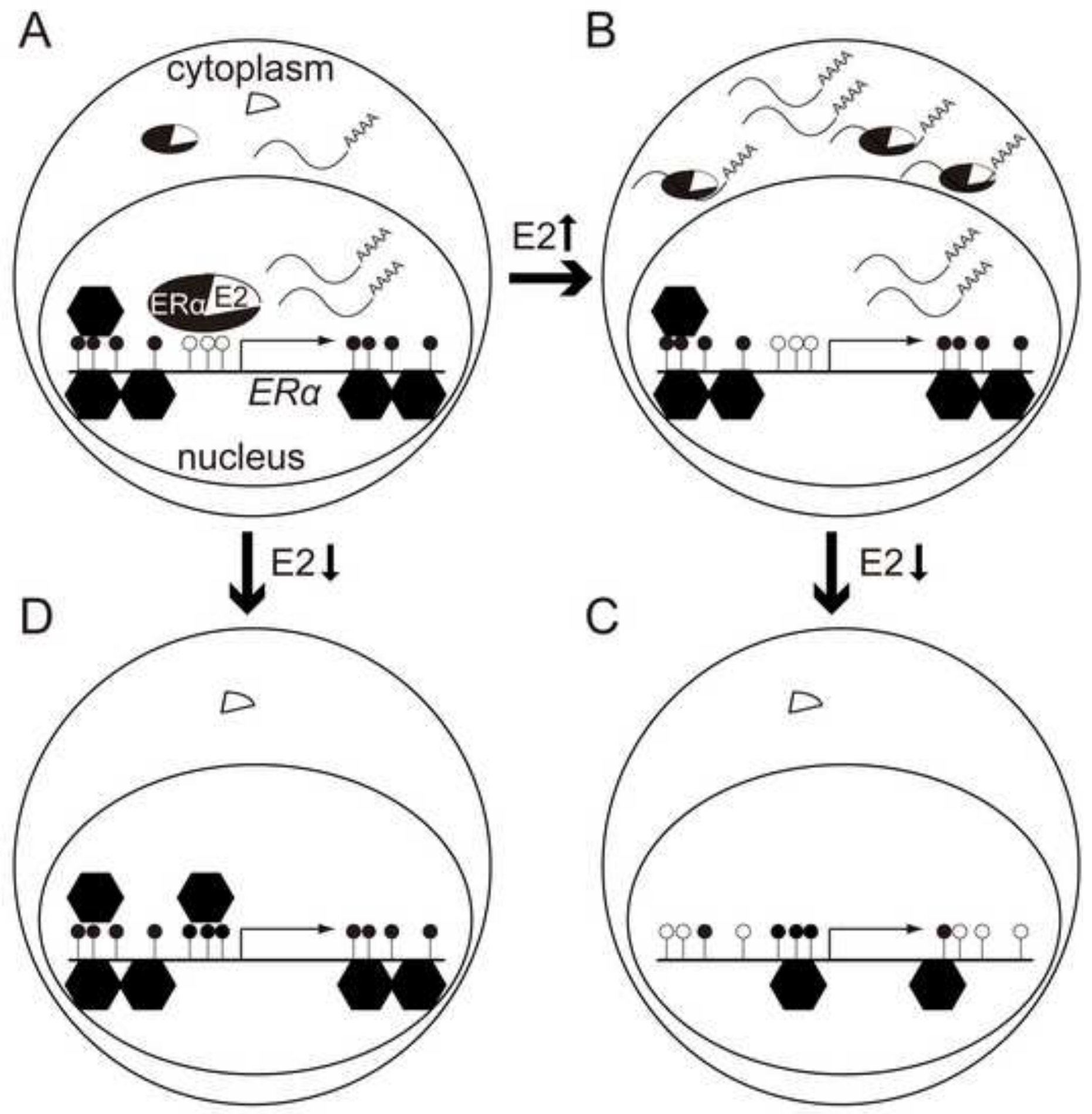

Figure 2 